\title{
Water temperature affects aggressive interactions in a Neotropical cichlid fish
}

\author{
Manuela L. Brandão ${ }^{1}$, Gisele Colognesi ${ }^{1}$, Marcela C. Bolognesi ${ }^{1,2}$, \\ Roselene S. Costa-Ferreira ${ }^{1}$, Thaís B. Carvalho ${ }^{3}$ and Eliane Gonçalves-de-Freitas ${ }^{1,2}$
}

Changes in water temperature may affect the aggressive behavior of aquatic organisms, such as fish, either by changing some physiological mechanisms or by increasing the probability of encounters between individuals as a result of variation in their swimming activity. In our study, we evaluated the influence of increasing and decreasing temperature on the aggressive behavior of the Neotropical cichlid fish Cichlasoma paranaense. Firstly, we tested the critical thermal maximum (CTMax) tolerated by this species. Then, we tested the effect of decreasing or increasing the water temperature in $6^{\circ} \mathrm{C}$ (starting at $27^{\circ} \mathrm{C}$ ) on the aggressive interactions of fish under isolation or housed in groups. We found a CTMax value of $39^{\circ} \mathrm{C}$ for $C$. paranaense. We also observe that a $6^{\circ} \mathrm{C}$ decrease in water temperature lowers swimming activity and aggressive interactions in both isolated and group-housed fish, as expected. On the other hand, the increase in temperature had no effect on the fish's aggressive behavior, neither for isolated nor for grouped fish. We concluded that $C$. paranaense shows high tolerance to elevated temperatures and, in turn, it does not affect aggressive behavior. Nevertheless, we cannot dismiss possible effects of elevated temperatures on aggressive interactions over longer periods.

Keywords: Agonistic behavior, Critical thermal maximum, Social hierarchy, Social isolation, Thermal environmental changes.

Mudanças na temperatura da água podem afetar o comportamento agressivo de organismos aquáticos, como peixes, seja alterando alguns mecanismos fisiológicos ou aumentando a probabilidade de encontros entre os indivíduos como um resultado da variação na sua atividade natatória. Em nosso estudo, nós avaliamos a influência do aumento e da diminuição da temperatura sobre o comportamento agressivo do peixe ciclídeo neotropical Cichlasoma paranaense. Primeiramente, nós testamos a temperatura crítica máxima (CTMax) tolerada por essa espécie. Depois disso, nós testamos o efeito de reduzir ou aumentar a temperatura da água em $6^{\circ} \mathrm{C}$ (a partir de $27^{\circ} \mathrm{C}$ ) sobre as interações agressivas de peixes sob isolamento ou alojados em grupos. Nós encontramos um valor de CTMax de $39^{\circ} \mathrm{C}$ para C. paranaense. Nós também observamos que uma redução de $6^{\circ} \mathrm{C}$ na temperatura da água diminui a atividade natatória e as interações agressivas tanto em peixes isolados quanto agrupados, como esperado. Por outro lado, o aumento na temperatura não teve efeito no comportamento agressivo dos peixes nem isolados, nem agrupados. Nós concluímos que C. paranaense apresenta alta tolerância a temperaturas elevadas, e que isso, por sua vez, não afeta o comportamento agressivo. No entanto, nós não podemos descartar possíveis efeitos de temperaturas elevadas sobre interações agressivas durante longos períodos.

Palavras-chave: Comportamento agonístico, Hierarquia social, Isolamento social, Mudanças ambientais térmicas, Temperatura crítica máxima.

\section{Introduction}

Environmental changes alter the physiology and behavior of animals, which allow them to deal with these new environmental conditions (Hofmann, Todgham, 2010; Wingfield, 2013). Such disturbances may be unexpected and demand immediate responses from individuals. These responses are part of what we call emergency life-history strategies (Wingfield, 2003), selected to help individuals cope with fluctuations in the environment (Wingfield, 2003). However, when some environmental changes surpass the individual's capacity of adjustment to deal with them, animals may collapse. Therefore, research concerning the effects of environmental changes on animal

\footnotetext{
${ }^{1}$ Laboratório de Comportamento Animal, Departamento de Zoologia e Botânica, Universidade Estadual Paulista (UNESP), Rua Cristóvão Colombo, 2265, 15054-000 São José do Rio Preto, SP, Brazil. (MLB) manulbrandao@gmail.com, Đhttps://orcid.org/0000-0002-8686-1076 (corresponding author), (GC) gikinhacolognesi@gmail.com, (MCB) marcelacbolognesi@gmail.com, (RSCF) roselene@ibilce.unesp.br ${ }^{2}$ Centro de Aquicultura da UNESP, Brazil. (EGF) elianeg@ibilce.unesp.br ${ }^{3}$ Laboratório de Fisiologia, Departamento de Ciências Fisiológicas, Universidade Federal do Amazonas (UFAM), Avenida General Rodrigo Otávio 6200,69077-000 Manaus, AM, Brazil. thaisbillalba@gmail.com
} 
behavior, especially those caused by climate change and anthropic actions (Walther et al., 2002; Bærum et al., 2013), has been increasing over the last years.

Riparian degradation, for example, is a type of disturbance with immediate effects on aquatic environments, causing a rise in water temperature, light incidence, evaporation, and siltation (Matthews, MarshMatthews, 2003). Changes in temperature may quickly affect the physiology and behavior of aquatic animals such as teleost fish, changing their metabolic rates (Kochhann et al., 2015; Campos et al., 2017), impairing their reproduction and modifying the individuals' personalities (Biro et al., 2010).

Therefore, upper and lower thermal tolerance limits are selected and fish will spend most of their lives in an optimal temperature range which allows the proper functioning of their physiological processes (Pörtner, 2010), and avoid temperatures outside their optimum range which can damage their cells and tissues and impair the individuals' health and survival (Motani, Wainwright, 2015).

Actually, temperatures close to the thermal tolerance limit may affect fish's aggressive behavior (e.g., the marine fish Tautoga onitis (Linnaeus, 1758); Olla et al., 1978). Elevated temperatures, for instance, may increase aggressive interactions, by raising their metabolic rate (Campos et al., 2017) and swimming activity (Beamish, 1978; Claireaux et al., 2006), which in consequence, increases the probability of aggressive encounters among some species of fish (Ratnasabapathi et al., 1992; Sakakura, Tsukamoto, 1997; Kochhann et al., 2015).

Thus, our aim was to test the effect of water temperature on aggressive interactions in a social Neotropical fish, Cichlasoma paranaense Kullander, 1983, to better understand how individuals cope with changes in the abiotic and social environment. We chose a fish from the Cichlidae family, comprised by social species which are socially ranked through aggressive interactions (Barlow, 2002; Shumway, 2010; Brandão et al., 2015); and also because $C$. paranaense inhabits Brazilian streams which are at deforestation risk and, consequently, undergo fast temperature variations. Therefore, we designed two studies; the first one aimed to test the critical thermal maximum (CTMax) tolerated by $C$. paranaense, under isolated and grouped conditions. In the second study, we tested the effects of elevated and reduced temperatures on the swimming activity and aggressive interactions of isolated and group-housed fish. Although it is a social species, we aimed to test isolated and grouped $C$. paranaense to understand how fish deal with environmental changes in the presence and absence of social group interferences. We predicted that high temperatures would increase the individuals' swimming activity and it would indirectly increase aggressive encounters among animals, whereas a decrease in water temperature would have an opposite effect, reducing aggressive interactions.

\section{Materials and Methods}

Animals and experimental conditions. Cichlasoma paranaense juveniles of unidentified sex (members of this species are sexually monomorphic) were captured from water bodies in the city of Frutal, MG, Brazil (20 $03^{\prime} 37.40^{\prime \prime}$ $\mathrm{S}$ and $49^{\circ} 12^{\prime} 16.09^{\prime \prime} \mathrm{W}$ ), and held in outdoor tanks at the Instituto de Biociências, Letras e Ciências Exatas, IBILCE/ UNESP, São José do Rio Preto, SP, Brazil. We chose to use sexually immature juveniles as it is known from another study with cichlid fish that males and females may fight differently when adults (Arnott, Elwood, 2009). Therefore, in order to avoid the effect of sex steroid hormone surges on aggressive behavior, we decided to study juvenile fish. A voucher specimen was deposited in the UNESP fish collection, in São José do Rio Preto, SP, Brazil, (DZSJRPPisces 13046).

The fish were acclimated to laboratory conditions in 500 $\mathrm{L}$ indoor tanks (ca. 1 fish $/ 5 \mathrm{~L} ; 27^{\circ} \mathrm{C}$ and $12 \mathrm{~h}$ light/dark cycles) for 15 days. Biological filters and constant aeration ensured water quality. Fish were fed twice a day to satiation with a commercial diet for tropical fish, Pirá ${ }^{\circledR} 28 \%$ protein.

For both studies, fish were isolated in glass aquaria (40 $\times 30 \times 40 \mathrm{~cm}$; ca. $48 \mathrm{~L}$ ) which had their side and back walls covered with blue plastic to prevent visual contact between replicates; blue plastic was chosen because this color is known to prevent stress in Oreochromis niloticus (Linnaeus 1758), which is also a cichlid fish species (Volpato, Barreto, 2001). Before the experiments, each fish was anaesthetized with tricaine methanesulfonate (MS222; Sigma-Aldrich, China; $20 \mathrm{mg} / \mathrm{L}$ ) to avoid stress during manipulation and, then, weighed and measured. After experiments, individuals were killed with an anesthetic overdose and dissected to confirm the gonadal stages macroscopically and confirm whether the fish were indeed immature.

Study 1 - Definition of a CTMax for Cichlasoma paranaense. In order to test the critical thermal maximum (CTMax) for $C$. paranaense, we conducted an experiment to identify the thermal point at which animals may lose motor capabilities, showing postural loss, which indicates an inability to escape from thermal situations that may lead to individuals' death (Cowles, Bogert, 1944). Fish were analyzed under both isolation and group-housed conditions.

CTMax for isolated fish. Isolated juveniles (standard length and weight of $8.24 \pm 0.5 \mathrm{~cm}$ and $24.1 \pm 7.45 \mathrm{~g}$, respectively; $\mathrm{n}=5$ ) were allocated individually in an aquarium, where they remained for two days at $27^{\circ} \mathrm{C}$ for habituation before beginning the temperature manipulation. $C$. paranaense inhabits the Paraná basin, whose temperature varies depending on the region and period of the year. Because there is no information regarding the ideal temperature for $C$. paranaense, we used the mean temperature considered for other cichlid species, which is $27^{\circ} \mathrm{C}$ (e.g., Figler, Einhorn, 1983; Schofield et al., 2010; Brandão et al., 2015). 
The water temperature was increased in $1^{\circ} \mathrm{C}$ per day with the use of heaters and thermostats. This increase in water temperature continued until we found that the fish had lost their corporal posture, revealing impaired swimming activity and, therefore, loss of an appropriate response to escape from a dangerous situation; we considered this to be the end point of the individuals' CTMax (Lutterschmidt, Hutchison, 1997). Behavioral quantification was carried out using videos (10 min each) recorded every two days to quantify their swimming activity. When fish started to lose their body posture, individuals were killed with an anesthetic overdose and dissected to confirm their immature gonadal stage.

CTMax in group-housed fish. After determining the CTMax for isolated fish, we grouped 3 fish (SL and weight of $7.6 \pm 0.71 \mathrm{~cm}$ and $24.1 \pm 7.45 \mathrm{~g}$, respectively; $\mathrm{n}=11$, total of 33 fish) under the same conditions of housing and manipulation described above. These individuals were addressed to the same temperature manipulation described for isolated ones.

Study 2 - Effect of temperature on aggressive behavior of isolated and group-housed fish. In the second study, we tested the effect of temperature variation on aggressive behavior in grouped and isolated fish, by means of three treatments: $21^{\circ} \mathrm{C}$ (decreased temperature, DT), $27^{\circ} \mathrm{C}$ (control temperature, $\mathrm{CT}$ ) and $33^{\circ} \mathrm{C}$ (increased temperature, IT) $\left(\mathrm{n}=12\right.$ each treatment), so that DT and IT were $6^{\circ} \mathrm{C}$ below or above the control, respectively. A recent study with several families of freshwater fish showed an average CTMax for these species of about $28.5^{\circ} \mathrm{C}$; the described cichlids support a maximum of $33.5^{\circ} \mathrm{C}$ average (Comte, Olden, 2017). Another study with a Neotropical cichlid [Amatitlania nigrofasciata (Günther, 1867), according to Ratnasabapathi et al., 1992] showed that a change of $4^{\circ} \mathrm{C}$ in water temperature was enough to affect their aggressive behavior. Based on these studies and the results from our first study regarding thermal tolerance, we chose a $6^{\circ}$ $\mathrm{C}$ variation in water temperature starting from $27^{\circ} \mathrm{C}$. The water temperature was controlled using heaters and thermostats manipulated in $2^{\circ} \mathrm{C}$ per day after the third day of experiment. All experiments were conducted in a laboratory equipped with an air conditioner, allowing us to achieve the DT as well.

Before experiments began, the oxygen concentration was measured daily using an oximeter to monitor whether the treatments DT, CT and IT would present low oxygen concentrations, resulting in a hypoxic environment for the fish, which could affect their aggressive behavior (Kochhann et al., 2015). We conducted this oxygen monitoring as a baseline for the experiments, and it was carried out in tanks filled only with water. The mean oxygen concentrations (partial pressure of oxygen, $\mathrm{PO}_{2}$ ) on the last day of experiment for each treatment were: $166 \mathrm{mmHg}$ (DT), $132 \mathrm{mmHg}$ (CT) and $118 \mathrm{mmHg}$ (IT). All treatments corresponded with oxygen concentrations considered as normoxia for cichlid fish (e.g., Chippari-Gomes et al., 2005; Schofield et al., 2009; Kochhann et al., 2015). Moreover, during the experiments, tanks were supplied with artificial aeration in all treatments.

Swimming activity and aggressive interactions in isolated fish. Twelve individuals were isolated for 3 days at CT for habituation under experimental conditions (SL and weight of $7.15 \pm 0.32 \mathrm{~cm}$ and $18.11 \pm 1.77 \mathrm{~g}$, respectively). After this period, the temperature was gradually decreased to the DT $\left(2^{\circ} \mathrm{C} /\right.$ day $)$, maintained at the $\mathrm{CT}$ or raised to the IT $\left(2^{\circ} \mathrm{C} /\right.$ day $)$. After achieving the three experimental conditions, the fish remained isolated for two more days.

We evaluated the effects of temperature on the swimming activity of isolated individuals. During the third and eighth days of temperature manipulation, the latency of their swimming activity was quantified through 10 -minute video recordings (Olla et al., 1978). We compared the swimming activity on the third and eighth days of experiment. The third day was the last day at control temperature and the eighth day was the last day after temperature was manipulated for all the treatments.

Aggressive behavior exhibited towards a mirror (e.g., mirror-elicited fights: Barreto et al., 2009; Falsarella et al., 2017) were recorded in two 15-minute videos; the first recording was made on the third day of the experiment, with all treatments at CT, and the second recording was made on the eighth day, when final temperatures had been reached. As we did for the swimming activity, we compared these two observations to determine whether there was a difference in aggressive interactions among the treatments after the change in temperature. Here, we chose to use isolated fish confronted with their mirror image to determine individual aggressive responses when faced with temperature changes, without any interference from the social group. Aggressive interactions were observed after we introduced a mirror $(30 \times 30 \mathrm{~cm})$ to one side of the aquarium during the video recordings. The frequency of aggressive interactions was achieved by means of mirror-elicited fights as it has already been done for other fish species (Oliveira et al., 2005; Scherer et al., 2016; Ivy et al., 2017). Fish cannot recognize their own image reflected in a mirror, therefore they will fight with their image as it were a real opponent (Falsarella et al., 2017). Thus, such mirror test is an efficient way to control for individual responses to variables such as the opponent's sex, size and previous social ranks (Balzarini et al., 2014), which could bias the focal fish's aggressive responses. The aggressive interactions observed here were based on an ethogram developed for $C$. paranaense (Brandão et al., 2015) and adjusted for mirror interactions, as described for the cichlid Astronotus ocellatus (Agassiz, 1831) by Gonçalves-de-Freitas, Mariguela (2006). Four types of aggressive behaviors were observed: frontal exhibition, lateral exhibition, butting and undulation. These behaviors were then grouped into overt aggression and restrained aggression. Generally, restrained aggressions are 
interactions with absence of physical contact, involving only displays of a hierarchical rank, whereas overt aggressions are physical encounters that demand a higher energy cost and may result in body injuries (Ros et al., 2006; Hellmann, Hamilton, 2014). Thus, behaviors such as frontal and lateral exhibition were considered restrained aggression, whereas butting and undulation were considered overt aggression.

Aggressive interactions in group-housed fish. We evaluated the aggressive interactions among 3 grouped fish of homogeneous size (standard length and weight of $7.62 \pm$ $0.86 \mathrm{~cm}$ and $24.12 \pm 8.91 \mathrm{~g}$, respectively). We maintained the same experimental conditions as used for isolated fish: treatments DT $\left(21^{\circ} \mathrm{C}\right)$, CT $\left(27^{\circ} \mathrm{C}\right)$ and IT $\left(33^{\circ} \mathrm{C}\right)$, with $\mathrm{n}=12$ each (total of 108 fish used). In this experiment, aggressive interactions were quantified using two 10-minute video recordings, one on the third day and another on the eighth day after fish were grouped.

We quantified the same aggressive behaviors described for isolated fish; however, here the behaviors were displayed against a real opponent. We classified lateral exhibition and lateral threat as restrained aggression, and undulation and lateral attack as overt aggression.

Statistical analysis. Data were tested for normality by Skewness and Kurtosis and for homoscedasticity by the $\mathrm{F}$ max test (Zar, 2010; Ha, Ha, 2011) and were log-transformed to fit into the parametric tests. Both the swimming activity and the frequency of aggressive interactions of isolated and group-housed fish were tested by Mixed Model ANOVA, to compare between $\left(21^{\circ}, 27^{\circ}\right.$ and $\left.33^{\circ} \mathrm{C}\right)$ and within (third and eighth days) treatments, completed by Fisher LSD post hoc test. We assumed $p<0.05$ for statistical significance.

\section{Results}

Study 1 - Definition of a CTMax for Cichlasoma paranaense. CTMax for isolated fish. All the isolated individuals lost corporal posture at the temperature of $39^{\circ} \mathrm{C}$, while at $41^{\circ}$ C, $66 \%$ of them were assumed as dead, with no opercular movements, as stated by Carter et al., 2011. Therefore, we settled $39^{\circ} \mathrm{C}$ as the CTMax for this species when individuals were isolated.

CTMax and aggressive interactions in group-housed fish. When the water temperature reached $37^{\circ} \mathrm{C}, 66 \%$ of replicates had at least one dead fish. The dead fish had several body and head injuries, suggesting that they died after suffering overt aggression from the other individuals in the group. Thus, although we observed that CTMax was $39^{\circ} \mathrm{C}$ for isolated individuals, the social group was affected by aggressive interactions. Postural loss was never observed for the remaining fish, thus such a criterion could not be used to infer CTMax. Therefore, aiming to avoid individuals' mortality during this phase, we chose to maintain the fish group at $35^{\circ}$ $\mathrm{C}$ as a safe margin for individual survival.
Swimming activity and aggressive interactions in isolated fish. For the first three days of experiment, the mean $\pm \mathrm{SE}$ water temperature was $26.9 \pm 0.2^{\circ} \mathrm{C}$ in all treatments. For the last three days, each treatment presented the mean temperature as proposed in the experimental design $\left(20.8^{\circ} \pm 0.1^{\circ} \mathrm{C}, 26.9^{\circ} \pm 0.1^{\circ} \mathrm{C}\right.$ and $33.1^{\circ} \pm 0.2^{\circ} \mathrm{C}$ for DT, CT and IT, respectively). The results were evaluated as follows:

The comparison of the third and eighth days of the swimming activity was significant among treatments $\left(F_{2,33}=15.04, p<0.0001\right.$; Fig. 1$)$. There was a significant reduction in the swimming activity at DT compared to CT $(p=0.01)$ and IT $(p<0.0001)$. The swimming activity was also higher at IT when compared to CT $(p<$ 0.001 ) (Fig. 1). When compared within treatments, both CT $(p=0.03)$ and IT $(p<0.0001)$ showed an increase in the individuals' swimming activity over the days of experiments.

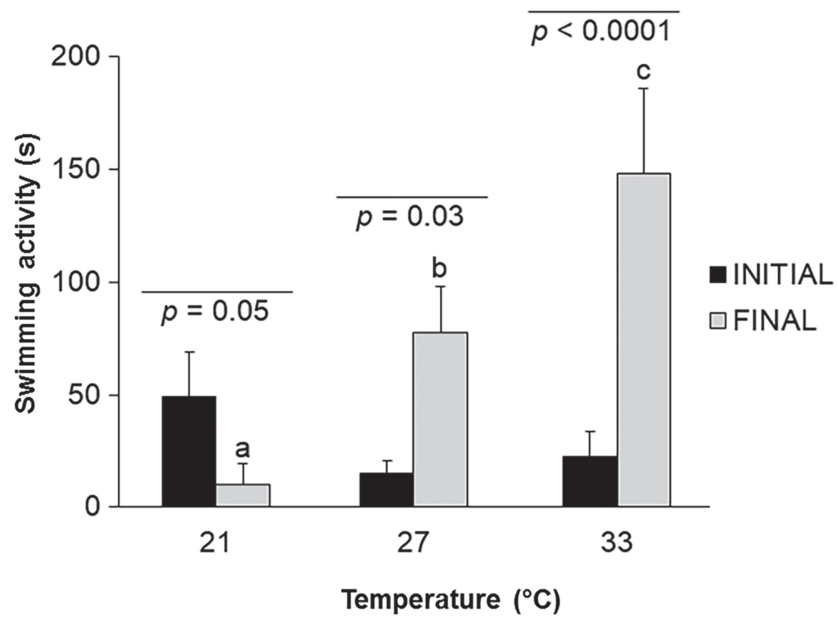

Fig. 1. Mean $\pm \mathrm{SE}$ of initial (third day) and final (eighth day) latency of swimming activity of isolated fish Cichlasoma paranaense. Different letters indicate statistical significance among treatments. Mixed Model ANOVA completed by Fisher-LSD post hoc test.

There were differences among and within treatments when the frequency of restrained aggression in the final observation (eighth day) was compared to that in the initial one (third day) $\left(F_{2,29}=30.78 ; p<0.001\right.$; Fig. 2a). Comparing initial observations, the DT did not differ from the CT ( $p$ $=0.34)$ or the IT treatments $(p=0.2)$, but CT and IT had lower frequencies of restrained aggression during the initial observation ( $p=0.03$ ) (Fig. 2a). The restrained aggression noticed in the final observations was lower for DT when compared to CT $(p=0.04)$ and IT $(p=0.04)$, whereas the frequencies of restrained aggression performed during the final observations were similar between CT and IT ( $p=$ 0.9 ) (Fig. 2a). There was an increase in the frequency of restrained aggression over the experiment days at CT $(p<$ $0.001)$ and IT $(p=0.01)$, but there was no difference at DT $(p=0.06)$ (Fig. 2a). 

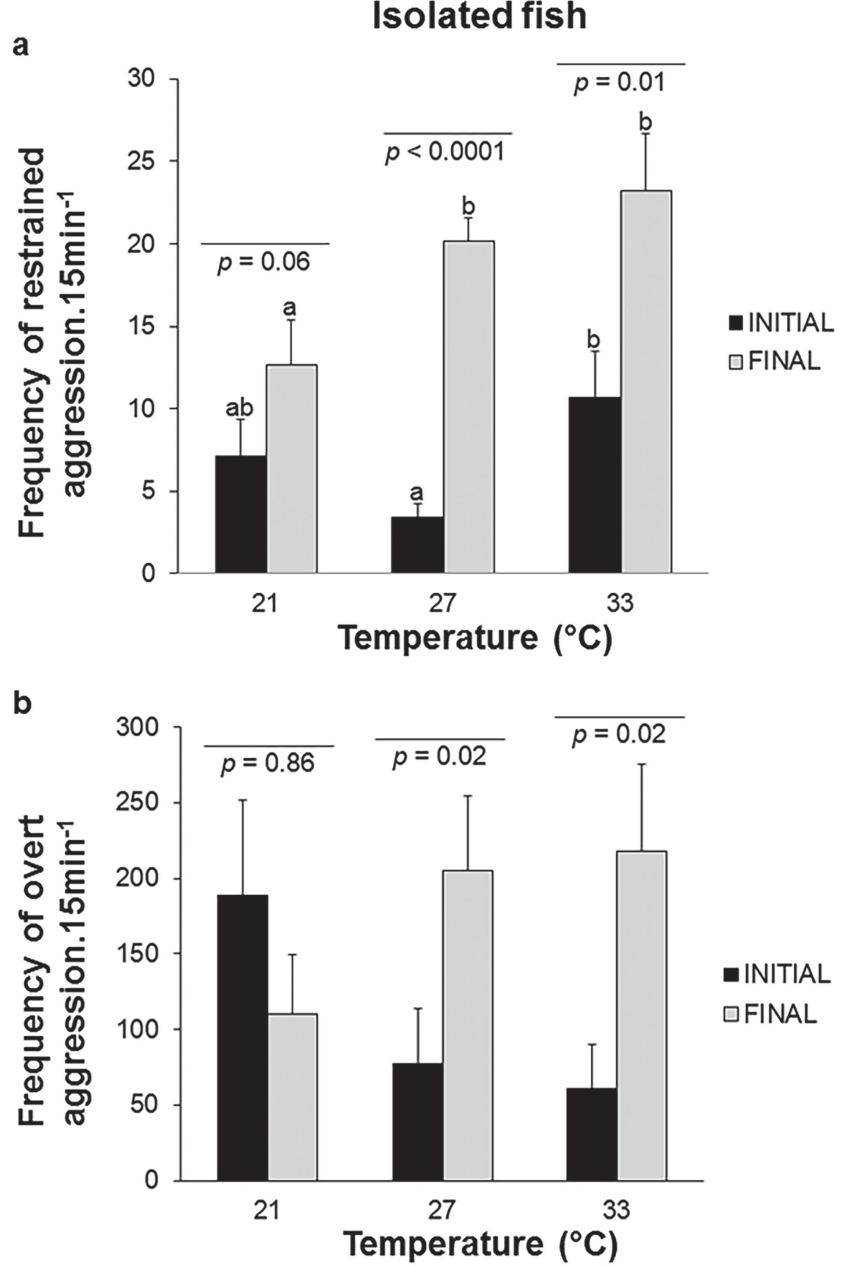

Fig. 2. Mean \pm SE of initial (third day) and final (eighth day) frequencies of $\mathbf{a}$. restrained aggression and $\mathbf{b}$. overt aggression of isolated fish against the mirror for Cichlasoma paranaense. Different letters show differences among treatments. Mixed Model ANOVA completed by Fisher-LSD post hoc test.

We also found significant differences when comparing the frequencies of initial and final overt aggression between and within treatments $\left(F_{2,29}=6.93 ; p=0.01 ;\right.$ Fig. $\left.2 b\right)$. The frequency of overt aggression was similar when comparing the initial and final observations between treatments (DT and CT, $p=0.3$ and $p=0.1$, respectively; DT and IT, $p=$ 0.3 and $p=0.08$; CT and IT, $p=0.9$ and $p=0.75$ ) (Fig. 2b); however, we detected more overt aggression when the initial and final observations were compared within CT $(p=0.02)$ and IT $(p=0.02)$.

Aggressive interactions in group-housed fish. For the first three days of experiment, the mean $\pm \mathrm{SE}$ water temperature was $27.1 \pm 0.2^{\circ} \mathrm{C}$. For the last two days, each treatment had the proposed values, that is, water temperatures were at $21.8^{\circ} \pm 0.2^{\circ} \mathrm{C}, 27.2^{\circ} \pm 0.1^{\circ} \mathrm{C}$ and $32.8^{\circ} \pm 0.2^{\circ} \mathrm{C}$ for DT, CT and IT, respectively.

There were significant differences among and within treatments when we compared the frequency of restrained aggression in the final (eighth day) and initial observations (third day) $\left(F_{2,33}=9.69 ; p=0.003\right.$; Fig. 3a). There was no difference in the initial observation of restrained aggression at DT in relation to CT $(p=0.65)$ or IT $(p=0.07)$. Nevertheless, there was a decrease in restrained aggression in the final observations of DT when compared to CT ( $p$ $=0.01)$ and IT $(p<0.001)$ (Fig. 3a). CT and IT were not different concerning the initial $(p=0.18)$ and final $(p=$ 0.23 ) observations of restrained aggression (Fig. 3a).

We also observed differences when comparing the initial and final frequencies of overt aggression between and within treatments $\left(F_{2,33}=8.68 ; p=0.005 ;\right.$ Fig. $\left.3 b\right)$. There were no differences in initial observations between DT and CT ( $p=$ $0.38)$, nor between DT and IT ( $p=0.37)$; however, there were lower frequencies of overt aggression during the final observations for treatments DT and CT $(p=0.005)$, and DT and IT ( $p=0.001)$ (Fig. 3b). CT and IT did not differ from each other in either the initial observations $(p=0.08)$, nor in the final ones ( $p=0.69)$ (Fig. 3b).

\section{Group-housed fish}

a
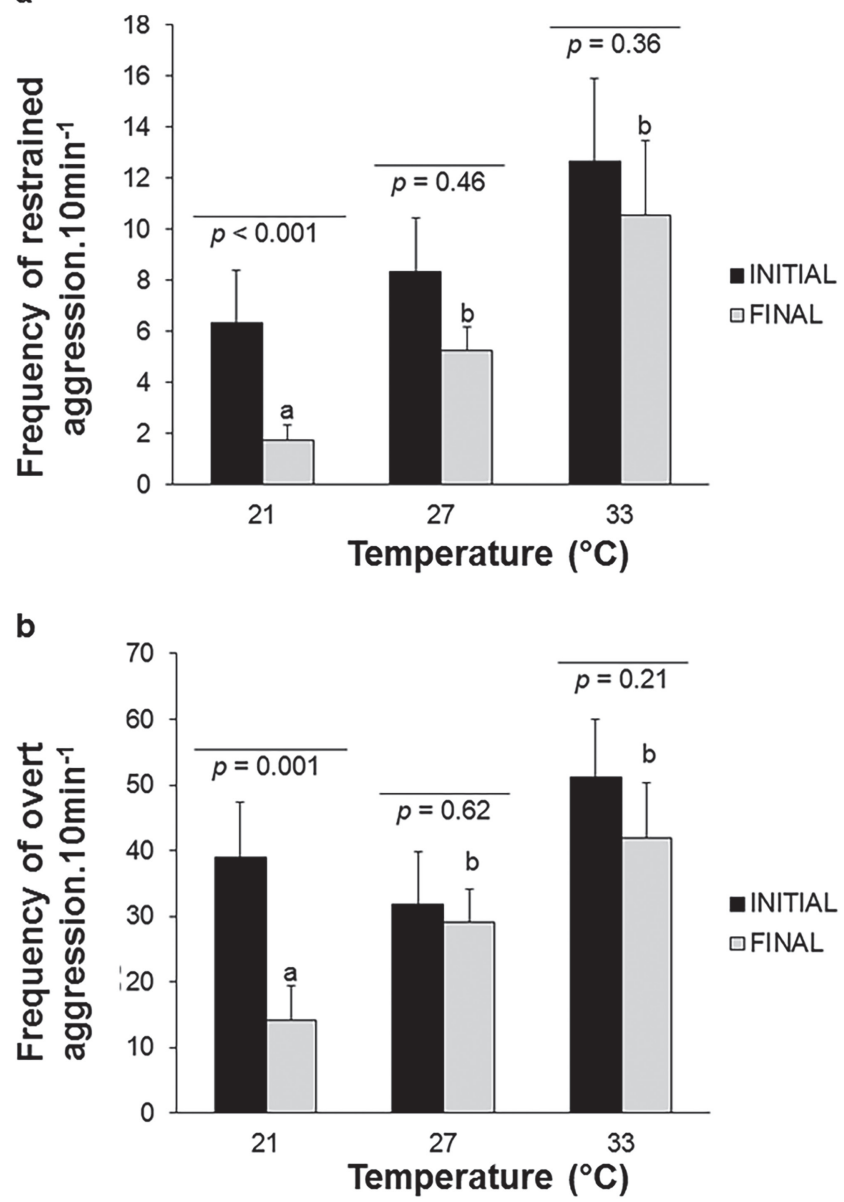

Fig. 3. Mean \pm SE of initial (third day) and final (eighth day) frequencies of a. restrained aggression and $\mathbf{b}$. overt aggression of group-housed fish. Different letters show differences among treatments. Mixed Model ANOVA completed by Fisher-LSD post hoc test. 


\section{Discussion}

In this study, we found CTMax for Cichlasoma paranaense to be $39^{\circ} \mathrm{C}$ for isolated fish. For group-housed fish, however, we found that $37^{\circ} \mathrm{C}$ increases mortality within the group due to aggressive interactions, thus suggesting that an increase in both temperature and social aggression will increase mortality before fish can reach a CTMax under such conditions. As expected, the different water temperatures affected their swimming activity at both DT and IT for isolated fish. In relation to study 2 , we observed stabilized aggressive interactions at DT when individuals were isolated, whereas CT and IT showed increased aggressive interactions on the final days of the experiment. For group-housed fish, decreased temperatures indeed reduced aggressive interactions, whereas at increased temperatures aggressive interactions were the same on the first and last days, as we also observed for the control treatment.

Cichlasoma paranaense seems to tolerate increased temperatures well. In our first study, isolated individuals of C. paranaense presented a CTMax of $39^{\circ} \mathrm{C}$, at which $100 \%$ of the fish showed a loss of corporal posture. When we tried to use the CTMax of $39^{\circ} \mathrm{C}$ for group-housed fish, however, we observed that $66 \%$ of the replicates had at least one fish that died at a water temperature as low as $37^{\circ} \mathrm{C}$. As we manipulated $1^{\circ} \mathrm{C}$ each day, but recorded aggressive interactions only after two days of this manipulation, we could not determine fish mortality at $36^{\circ} \mathrm{C}$, thus, as a safety margin, we chose to settle the temperature at $35^{\circ} \mathrm{C}$ to observe the behavior of group-housed C. paranaense. Therefore, we could not determine CTMax for group-housed fish, as we did not observe any postural loss in this experiment. Nevertheless, CTMax found for isolated individuals shows that $C$. paranaense is a very tolerant species to increased water temperatures when compared to other freshwater fish (e.g., average CTMax of $28.5^{\circ} \mathrm{C}$ for several fish species; Comte, Olden, 2017). This was also found for other cichlids such as Pterophyllum scalare (Schultze. 1823), Etroplus suratensis (Bloch, 1790) and Geophagus brasiliensis (Quoy \& Gaimard, 1824), which show a CTMax of $40^{\circ} \mathrm{C}$ (Pérez et al., 2003) and $35^{\circ} \mathrm{C}$ (Comte, Olden, 2017), and a lethal temperature of $32^{\circ} \mathrm{C}$ (Rantin, Petersen, 1985), respectively.

Concerning study 2 , the treatments $21^{\circ} \mathrm{C}$ (DT), $27^{\circ}$ $\mathrm{C}(\mathrm{CT})$ and $33^{\circ} \mathrm{C}$ (IT) for isolated fish resulted in the same frequencies of restrained aggression in the initial observations, showing the same performance to display these behaviors. However, after the water temperature manipulation, on the final day of observation, fish showed the same performance when fighting at DT as on the first days, whereas at CT and IT, the individuals increased their aggressive interactions. When isolated at $\mathrm{CT}$ and IT, fish showed more restrained aggression on the final days. This was not expected for CT, at which we had anticipated a stable frequency of restrained aggression between the initial and final observations, due to the absence of temperature manipulation. In fact, an additional effect of social isolation seems to have affected individual aggressive performance, as it is already known for other teleost fish species (GómezLaplaza, Morgan, 2000; Gonçalves-de-Freitas, Mariguela, 2006). This increased aggressive behavior after isolation may be also linked to the previously described emergency life-history stages (Wingfield, 2003), indicating that the individuals are under social stress, which could explain the rise in aggressive interactions seen for $C$. paranaense at CT similarly to IT. Concerning the frequency of overt aggression, we also observed a higher number of aggressive interactions being performed in the final observations for individuals at CT and IT, again revealing a possible effect of social isolation increasing aggressiveness, masking the real effect of temperature in these treatments.

An alternate explanation regarding the change in aggression levels is that social communication was impaired. According to Giaquinto, Volpato (1997) and Gonçalvesde-Freitas et al. (2008), chemical and visual signals from contestant fish are required to complete the social rank recognition in the Nile tilapia. Therefore, the mirror image could have offered incomplete information about the "virtual" opponent, which may have led to the continuous overt aggression displayed by isolated fish (Gonçalves-deFreitas, Mariguela, 2006).

Regarding group-housed fish, there were lower frequencies of restrained and overt aggression at DT, as expected. In terms of aggressive behavior, all three treatments started with the same fighting performance and no differences among their initial observations were seen. Concerning restrained aggression, the final observation for DT revealed a decrease in this behavior compared to the restrained aggression seen in the initial observation. The final observation for DT was also different from the final observations for CT and IT, which was also seen for overt aggression, showing a reduction in the last days compared to the initial ones at DT and when compared to the last observations in the other two treatments, CT and IT. These results corroborated with part of our hypothesis, revealing that a decrease of $6^{\circ} \mathrm{C}$ in water temperature would lead to reduced aggressive interactions in $C$. paranaense, probably as a consequence of reduced swimming activity at $21^{\circ} \mathrm{C}$, showing a possible influence of water temperature on the individual's metabolism (e.g., Claireaux et al., 2006; Pang et al., 2011; Vergauwen et al., 2013; Campos et al., 2017). Nevertheless, this was not the case for $33^{\circ} \mathrm{C}$, where initial and final aggressive interactions had no difference, besides the increased swimming activity observed at this temperature. This species continues to respond in the same way to increased water temperature, which leads us to speculate that $C$. paranaense is not such a sensitive species regarding short-term temperature elevation and that the aggressive behavior of those individuals might not be affected over such a short period. Indeed, $C$. paranaense is considered to be a tolerant species, with a high survival rate in impacted environments (Casatti et al., 2009) and possibly able to tolerate increased temperatures. In regard to the CT treatment, we expected that aggressive interactions would 
be stable over the days of observation and it occurred as anticipated. Maintaining the water temperature at $27^{\circ} \mathrm{C}$ was effective in stabilizing fights among C. paranaense when the animals were housed in groups. The IT treatment did not show an increase in aggressive interactions among individuals over the days of observation as well. Thus, an increase of $6^{\circ} \mathrm{C}$ in water temperature did not affect aggressive interactions at IT, contradicting some of our expectations. However, our results are in accordance with studies conducted by O'Mara, Wong (2015), in which increased temperature had no effect on the aggression levels of the Australian bass, Macquaria novemaculeata (Steindachner, 1866). This means that the aggressive response depends on the fish species.

When analyzing restrained and overt aggression at the DT treatment, we showed that a decrease in water temperature led to a reduction in the aggressive interactions of $C$. paranaense. These results are similar to those found by Vehanen et al. (2000), which showed decreased aggressive interactions among the brown trout, Salmo trutta Linnaeus, 1758 , in the winter season, when compared to the summer. Thus, the effect of reduced temperatures on aggressive behavior seems to be more generalized among fish species than the effect of increased temperatures.

Our study shows that a decrease in water temperature reduces individuals' swimming activity and aggressive interactions, probably due to a decrease in aggressive encounters between individuals. We also show that, for isolated C. paranaense individuals, CTMax is $39^{\circ} \mathrm{C}$, being probably inferior for group-housed fish. This investigation revealed how environmental changes, such as temperature, may influence the behavior of social fish, which have to cope with these natural emergencies modulating their aggressive interactions. Despite the findings shown here, long-term effects of temperature and many other factors relating to habitat deterioration on fish's social behavior are crucial and must be intensively investigated, raising questions for future studies. Moreover, the behavior of $C$. paranaense is little known, and information associating physical and environmental alterations with aggressive behavior may support plans to conserve aquatic environments and the fish that inhabit them.

\section{Acknowledgments}

We thank Vinicius Sabadim Fernandes for technical assistance during data collection. This study was supported by Fundação de Amparo à Pesquisa do Estado de São Paulo by means of a grant to MLB (FAPESP, grant number 2011/01683-9), by Conselho Nacional de Desenvolvimento Científico e Tecnológico by means of a grant to EGF (CNPq, grant number 308237/2010-2), and by Fundação de Amparo à Pesquisa do Estado do Amazonas (FAPEAM, EDITAL N. 015/2014- PAPAC). MCB was supported by FAPESP (grant number 2012/05498-4). This study was approved by the Ethical Committee of Animal Experimentation of UNESP, SP, Brazil (permit 024/2010).

\section{References}

Arnott G, Elwood RW. Gender differences in aggressive behaviour in convict cichlids. Anim Behav. 2009; 78(5):1221-27.

Bærum KM, Haugen TO, Kiffney P, Olsen EM, Vøllestad LA. Interacting effects of temperature and density on individual growth performance in a wild population of brown trout. Freshwater Biol. 2013; 58(7):1329-39.

Balzarini V, Taborsky M, Wanner S, Koch F, Frommen JG. Mirror, mirror on the wall: the predictive value of mirror tests for measuring aggression in fish. Behav Ecol Sociobiol. 2014; 68(5):871-78.

Barlow G. The cichlid fishes: nature's grand experiment in evolution. 1st ed. New York: Basic Books; 2002.

Barreto RE, Volpato GL, Faturi CD, Giaquinto PC, Gonlçavesde-Freitas E, Castilho MF. Aggressive behaviour traits predict physiological stress responses in Nile tilapia (Oreochromis niloticus). Mar Freshw Behav Phy. 2009; 42(2):109-18.

Beamish FWH. Swimming capacity. In: Hoar WS, Randall DJ, editors. Fish physiology. New York: Academic Press; 1978. p.101-187. (Fish physiology; vol 7).

Biro PA, Beckmann C, Stamps JA. Small within-day increases in temperature affects boldness and alters personality in coral reef fish. Proc R Soc B. 2010; 277(1678):71-77.

Brandão ML, Braithwaite VA, Gonçalves-de-Freitas E. Isolation impairs cognition in a social fish. Appl Anim Behav Sci. 2015; 171:204-10.

Campos DF, Jesus TF, Kochhann D, Heinrichs-Caldas W, Coelho MM, Almeida-Val VMF. Metabolic rate and thermal tolerance in two congeneric Amazon fishes: Paracheirodon axelrodi Schultz, 1956 and Paracheirodon simulans Géry, 1963 (Characidae). Hydrobiologia. 2017; 789(1):133-42.

Carter KM, Woodley CM, Brown RS. A review of tricaine methanesulfonate for anesthesia of fish. Rev Fish Biol Fisher. 2011; 21(1):51-59.

Casatti L, Ferreira CP, Langeani F. A fish-based biotic integrity index for assessment of lowland streams in southeastern Brazil. Hydrobiologia. 2009; 623(1):173-89.

Chippari-Gomes AR, Gomes LC, Lopes NP, Val AL, AlmeidaVal VML. Metabolic adjustments in two Amazonian cichlids exposed to hypoxia and anoxia. Comp Biochem Physiol B Biochem Mol Biol. 2005; 141(3):347-55.

Claireaux G, Couturier C, Groison AL. Effect of temperature on maximum swimming speed and cost of transport in juvenile European sea bass (Dicentrarchus labrax). J Exp Biol. 2006; 209(Pt17):3420-28.

Comte L, Olden JD. Evolutionary and environmental determinants of freshwater fish thermal tolerance and plasticity. Global Change Biol. 2017; 23(2):728-36.

Cowles RB, Bogert CM. A preliminary study of the thermal requirements of desert reptiles. B Am Mus Nat Hist. 1944; 83(5): 261-96.

Falsarella LN, Brandão ML, Gonçalves-de-Freitas E. Fish adjust aggressive behavior to audience size with limited information on bystanders' fighting ability. Behav Process. 2017; 142:116-18.

Figler MH, Einhorn DM. The territorial prior residence effect in convict cichlids (Cichlasoma nigrofasciatum Günther): temporal aspects of establishment and retention, and proximate mechanisms. Behaviour. 1983; 85(1):157-83.

Giaquinto PC, Volpato GL. Chemical communication, agression, and conspecific recognition in the fish Nile tilapia. Physiol Behav. 1997; 62(6):1333-38. 
Gómez-Laplaza LM, Morgan E. Laboratory studies of the effects of short-term isolation on aggressive behaviour in fish. Mar Freshw Behav Phy. 2000; 33(2):63-102.

Gonçalves-de-Freitas E, Mariguela TC. Social isolation and aggressiveness in the Amazonian juvenile fish Astronotus ocellatus. Braz J Biol. 2006; 66(1B):233-38.

Gonçalves-de-Freitas E, Teresa FB, Gomes FS, Giaquinto PC. Effect of water renewal on dominance hierarchy of juvenile Nile tilapia. Appl Anim Behav Sci. 2008; 112(1-2):187-95.

Ha RR, Ha JC. Integrative statistics for the social and behavioral sciences. 1st ed. Thousand Oaks: SAGE Publishing; 2011.

Hellmann JK, Hamilton IM. The presence of neighbors influences defense against predators in a cooperatively breeding cichlid. Behav Ecol. 2014; 25(2):386-91.

Hofmann GE, Todgham AE. Living in the now: physiological mechanisms to tolerate a rapidly changing environment. Annu Rev Physiol. 2010; 72:127-45.

Ivy CM, Robertson CE, Bernier NJ. Acute embryonic anoxia exposure favours the development of a dominant and aggressive phenotype in adult zebrafish. Proc R Soc B. 2017; 284(1846):20161868. Available from: https://doi.org/10.1098/ rspb.2016.1868

Kochhann D, Campos DF, Val AL. Experimentally increased temperature and hypoxia affect stability of social hierarchy and metabolism of the Amazonian cichlid Apistogramma agassizii. Comp Biochem Physiol A Mol Integr Physiol. 2015; 190:54-60.

Lutterschmidt WI, Hutchison VH. The critical thermal maximum: history and critique. Can J Zool. 1997; 75(10):1561-74.

Matthews WJ, Marsh-Matthews E. Effects of drought on fish across axes of space, time and ecological complexity. Freshwater Biol. 2003; 48(7):1232-53.

Motani R, Wainwright PC. How warm is too warm for the life cycle of actinopterygian fishes? Sci Rep-UK. 2015; 5:11597. Available from: https://dx.doi.org/10.1038/srep11597

O’Mara KM, Wong MYL. Body size mediated effects of multiple abiotic stressors on the growth and social behaviour of an estuarine fish, Australian Bass (Macquaria novemaculeata). Environ Biol Fish. 2015; 99(1):95-104.

Oliveira RF, Carneiro LA, Canário AVM. No hormonal response in tied fights. Nature. 2005; 437(7056):207-08.

Olla BL, Studholme AL, Bejda AJ, Samet C, Martin AD. Effect of temperature on activity and social behavior of the adult tautog Tautoga onitis under laboratory conditions. Mar Biol. 1978; 45(4):369-78.

Pang X, Cao ZD, Fu SJ. The effects of temperature on metabolic interaction between digestion and locomotion in juveniles of three cyprinid fish (Carassius auratus, Cyprinus carpio and Spinibarbus sinensis). Comp Biochem Physiol A Mol Integr Physiol. 2011; 159(3):253-60.

Pérez E, Díaz F, Espina S. Thermoregulatory behavior and critical thermal limits of the angelfish Pterophyllum scalare (Lichtenstein) (Pisces: Cichlidae). J Therm Biol. 2003; 28(8):531-37.

Pörtner HO. Oxygen- and capacity-limitation of thermal tolerance: a matrix for integrating climate-related stressor effects in marine ecosystems. J Exp Biol. 2010; 213(6):881-93.
Rantin FT, Petersen JA. Thermal tolerance of South American cichlid, Geophagus brasiliensis. Rev Hydrobiol Trop. 1985; 18(3):221-26.

Ratnasabapathi D, Burns J, Souchek R. Effects of temperature and prior residence on territorial aggression in the convict cichlid Cichlasoma nigrofasciatum. Aggressive Behav. 1992; 18(5):365-72.

Ros AFH, Becker K, Oliveira RF. Aggressive behaviour and energy metabolism in a cichlid fish, Oreochromis mossambicus. Physiol Behav. 2006; 89(2):164-70.

Sakakura Y, Tsukamoto K. Effects of water temperature and light intensity on aggressive behavior in the juvenile yellowtails. Fisheries Sci. 1997; 63(1): 42-45.

Scherer U, Buck M, Schuett W. Lateralisation in agonistic encounters: do mirror tests reflect aggressive behaviour? A study on a West African cichlid. J Fish Biol. 2016; 89(3): 1866-72.

Schofield PJ, Loftus WF, Fontaine JA. Salinity effects on behavioural response to hypoxia in the non-native Mayan cichlid Cichlasoma urophthalmus from Florida Everglades wetlands. J Fish Biol. 2009; 74(6):1245-58.

Schofield PJ, Loftus WF, Kobza RM, Cook MI, Slone DH. Tolerance of nonindigenous cichlid fishes (Cichlasoma urophthalmus, Hemichromis letourneuxi) to low temperature: laboratory and field experiments in south Florida. Biol Invasions. 2010; 12(8):2441-57.

Shumway CA. The evolution of complex brains and behaviors in African cichlid fishes. Curr Zool. 2010; 56(1):144-56.

Vehanen T, Bjerke PL, Heggenes J, Huusko A, Mäki-Petäys A. Effect of fluctuating flow and temperature on cover type selection and behaviour by juvenile brown trout in artificial flumes. J Fish Biol. 2000; 56(4):923-37.

Vergauwen L, Knapen D, Hagenaars A, De Boeck G, Blust R. Assessing the impact of thermal acclimation on physiological condition in the zebrafish model. J Comp Physiol B. 2013; 183(1):109-21.

Volpato GL, Barreto RE. Environmental blue light prevents stress in the fish Nile tilapia. Braz J Med Biol Res. 2001; 34(8):1041-45.

Walther G, Post E, Convey P, Menzel A, Parmesan C, Beebee TJC et al. Ecological responses to recent climate change. Nature. 2002; 416(6879):389-95.

Wingfield JC. Control of behavioural strategies for capricious environments. Anim Behav. 2003; 66(5):807-16.

Wingfield JC. Ecological processes and the ecology of stress: the impacts of abiotic environmental factors. Funct Ecol. 2013; 27(1):37-44.

Zar JH. Biostatistical Analysis. 4th ed. New Jersey: Prentice Hall. 2010. 